\title{
Recurrence of Kawasaki Disease in a Young Child
}

\author{
Jessica Bangert, Georgios Meridis and Eugen-Matthias Strehle*
}

\begin{abstract}
Child Health Department, Northumbria Health care NHS Foundation Trust, Cobalt Business Park, Newcastle upon Tyne NE27 0QJ, UK
\end{abstract}

\begin{abstract}
A diagnosis of Kawasaki disease (KD) is mainly based on clinical criteria. We discuss the case of a young boy who presented at the ages of 7 months and 13 months with signs and symptoms suggestive of Kawasaki disease. At the first episode he was treated for Kawasaki disease and at the second episode for lymphadenitis and fever. A diagnosis of recurrent KD was only made retrospectively when he developed thrombocytosis and desquamation of the extremities. Subsequent echocardiograms revealed no abnormalities. It is important that a diagnosis of KD is considered in any child presenting with a fever of more than 5 days irrespective of the previous medical history.
\end{abstract}

Keywords: Kawasaki disease, atypical, incomplete, recurrent.

\section{INTRODUCTION}

Kawasaki Disease (KD) is an acute systemic vasculitis, the etiology of which remains uncertain. It is now the leading cause of acquired cardiac disease in children under 5 years. Current evidence indicates an infectious causative agent, yet there is increasing suggestion that autoimmune reaction and genetic predisposition may play a part [1]. Diagnosis of KD continues to be based upon clinical criteria, as highlighted in Table 1a. Kawasaki disease is termed 'incomplete' when less than four of the obligatory criteria are present and 'atypical' when patients show a clinical characteristic that is not typically associated with this condition. [2]. Although the incidence is increasing particularly in Japan $(218 / 100,000), \mathrm{KD}$ is still uncommon in the UK $(8 / 100,000)$ [3]. Recurrence of the disease is even less frequent and is more likely to be atypical or incomplete [4]. We discuss a case of recurrent $\mathrm{KD}$, where diagnosis and treatment were delayed.

\section{CASE DESCRIPTION}

A 7-month-old male was admitted with 5 days of high fever, associated with irritability, red eyes and a rash. On examination, he had bilateral conjunctivitis and lymphadenopathy, red lips, and a maculopapular, blanching rash. Examination of other systems was unremarkable, and aside pyrexia, observations remained stable. Investigations demonstrated a raised inflammatory response and anaemia, with negative cultures and ASO titre (Table 1b). A throat swab was also negative but eye swab revealed Haemophilus influenza. He was treated with intravenous Immunoglobulins (IVIG) $2 \mathrm{~g} / \mathrm{kg}$ and commenced on Aspirin $12 \mathrm{mg} / \mathrm{kg}$ 6-hourly for 2 weeks, then decreased to $6 \mathrm{mg} / \mathrm{kg}$ daily for 8 weeks. The conjunctivitis was treated with chloramphenicol drops.

*Address correspondence to this author at the Department of Pediatrics, North Tyneside General Hospital, North Shields NE29 8NH, UK; Tel: 0044191 2031200; Fax: 0044191 2932520;

E-mail: strehle@doctors.org.uk
An uneventful recovery was made. Echocardiogram performed 1 month after discharge showed no coronary artery aneurysms or pericardial effusion, and good biventricular function.

Six months later the patient was readmitted with high fever and 1-day-history of a unilateral mass in the right side of his neck. This was felt to be an abscess which was treated with intravenous Benzylpenicillin and Flucloxacillin. However, a subsequent ultrasound scan of the neck revealed multiple enlarged lymph nodes measuring up to $25 \mathrm{~mm}$ on the right and several smaller lymph nodes on the left, with no evidence of an abscess. Temperatures peaking $>40{ }^{\circ} \mathrm{C}$ persisted for a week despite regular antipyretics alongside the antibiotics. During this time, the patient developed a rash over his trunk and forearms alongside reddened lips and eyes. Antibiotics were switched to Cefuroxime to broaden the spectrum.

Investigations demonstrated a similar picture to his previous admission (Table 1b).

Biochemical profile and immunoglobulins were unremarkable. Epstein-Barr virus, Cytomegalovirus and Mycoplasma antibody titres were negative. Neutrophil Oxidative Burst and Nitro-Blue Tetrazolium test were normal.

Recurrence of KD was considered but was deemed unlikely, and therefore IVIG was not given. An expert in infectious diseases was consulted who advised to add Clindamycin to treatment. Following discharge, a retrospective diagnosis of KD was made after further blood results showed thrombocytosis $\left(914 \times 10^{9} / \mathrm{L}\right)$ and parental reports of desquamation of the extremities. Follow-up echocardiograms after 2 months and 8 months showed no complications.

\section{DISCUSSION}

In this case we present a young boy who had recurrent $\mathrm{KD}$ with no complications. The diagnosis was delayed at the 
Table 1a. Diagnostic Criteria of KD in Relation to Case Report

\begin{tabular}{|c|c|c|}
\hline Features & $\mathbf{1}^{\text {st }}$ Presentation & $\checkmark$ \\
\hline \hline Fever $>5$ days & $\checkmark$ & $\checkmark$ \\
\hline Bilateral conjunctivitis & $\checkmark$ & $\checkmark$ \\
\hline Cervical lymphadenopathy & $\checkmark$ & $\checkmark$ \\
\hline Inflammation of lips \& tongue & $\checkmark$ & $\checkmark$ \\
\hline Rash & $\checkmark$ & $\checkmark$ \\
\hline Erythema, swelling \& desquamation of extremities & $\checkmark$ & \\
\hline
\end{tabular}

Table 1b. Investigation Findings (Figures as Mean with Range in Brackets)

\begin{tabular}{|c|c|c|}
\hline Investigation & $1^{\text {st }}$ Presentation & $2^{\text {nd }}$ Presentation \\
\hline Haemoglobin $\mathrm{g} / \mathrm{dl}$ & $9.9(9.2-10.8)$ & $9.8(9.3-10.3)$ \\
\hline White Blood Count $\times 10^{9} / \mathrm{L}$ & $13.2(10.4-17.8)$ & $16(11.3-21.3)$ \\
\hline Platelets $\times 10^{9} / \mathrm{L}$ & $285(160-370)$ & $441(202-914)$ \\
\hline C-Reactive Protein $\mathrm{mg} / \mathrm{L}$ & $122(6-207)$ & $213(8-314)$ \\
\hline ASO titre & Negative & Negative \\
\hline Blood/Urine/Stool Cultures & Negative & Negative \\
\hline Chest X-Ray & Normal & Not done \\
\hline
\end{tabular}

second presentation and therefore treatment with IVIG and aspirin was not given.

Diagnosis of $\mathrm{KD}$ is not simple due to the staggered nature of presenting features and lack of specific symptoms. In addition, sensitive laboratory tests are currently not available. There are recognized phases of $\mathrm{KD}$, and the almost pathognomonic features such as skin peeling of the extremities and coronary artery aneurysms do not occur until the later stages [2]. They have little influence on reaching a timely diagnosis and treatment with intravenous immunoglobulins and oral aspirin. Therefore, clinicians should include $\mathrm{KD}$ in their differential diagnosis in all patients presenting with any of the other disease characteristics listed in Table 1a. Naturally, atypical or incomplete Kawasaki disease poses an even greater diagnostic challenge.

Recurrent KD is mostly atypical and remains uncommon but recognized; $0.8 \%$ in US and 3\% in Japan [4]. Largely recurrence occurs within 2 years of the initial attack but can recur decades later [5]. Patients with recurrence are at increased risk of complications. Risk factors for sequelae of recurrence have been thought male sex and the presence of complications at initial episode [6].

Treatment with IVIG is known to be beneficial and needs to be administered within 10 day of onset of fever. Failure of treatment with IVIG is the most significant risk factor for KD patients developing coronary artery lesions (CAL) [7].

CAL such as giant aneurysms can become stenotic with the consequential risk of myocardial ischaemia in young adulthood. Although under debate, it has been suggested that coronary arteries that are normal at echogradiogram could be damaged or develop gradual intimal hyperplasia much after the presentation of KD [8].

This case should serve as a reminder that although $\mathrm{KD}$ is a difficult diagnosis to make, particularly when features are missing at initial presentation, it should be considered in the differential for any child with more than 5 days of fever and more so if there is a previous history of KD.

\section{CONFLICT OF INTEREST}

The authors confirm that this article content has no conflicts of interest.

\section{ACKNOWLEDGEMENT}

We are grateful to the parents for permitting publication.

\section{REFERENCES}

[1] Maconochie IK. Kawasaki Disease.Arch Dis Child Educ Pract Ed 2004, 89: ep3-ep8.

[2] Haftel HM. Kawasaki Disease. In: Marcdante KJ, Kliegman,RM, Jenson HB, Behrman RE, Eds. Nelson Essentials of Pediatrics. $6^{\text {th }}$ ed. Philadelphia: Saunders Elselvier, 2011; pp. 343-5.

[3] Uehara R, Belay ED. Epidemiology of Kawasaki disease in Asia, Europe, and the United States. J Epidemiol. 2012; 22: 79-85.

[4] Zou LX, Gong FQ. Clinical features of recurrent Kawasaki disease in 20 children. Zhongguo Dang Dai Er Ke Za Zhi 2008; 10: 617-9.

[5] Balasubramanian S, Ganesh R. Recurrent Kawasaki Disease. Ind J Pediatr 2009, 77: 848-9

[6] Nakamura Y, Oki I, Tanihara S, Ojima T, Yanagawa H. Cardiac sequelae in recurrent cases of Kawasaki disease: a comparison 
between the initial episode of the disease and a recurrence in the same patients. Pediatrics 1998, 102: e66.

[7] Wilder MS, Palinkas LA, Kao AS, Bastian JF, Turner CL, Burns JC. Delayed diagnosis by physicians contributes to the development of coronary artery aneurysms in children with Kawasaki syndrome. Pediatr Infect Dis J 2007; 26: 256-60.

[8] Falcini F. Kawasaki Disease. Curr Opin Rheumatol 2006, 18: 33-8.

Received: June 07, 2013

Revised: June 26, 2013

Accepted: June 26, 2013

(C) Bangert et al.; Licensee Bentham Open .

This is an open access article licensed under the terms of the Creative Commons Attribution Non-Commercial License (http://creativecommons.org/licenses/by$\mathrm{nc} / 3.0 /)$, which permits unrestricted, non-commercial use, distribution and reproduction in any medium, provided the work is properly cited. 